\title{
Review
}

\section{Heart, lipids and hormones}

Endocrine CONNECTIONS

\author{
Peter Wolf1, Yvonne Winhofer ${ }^{1}$, Martin Krššák ${ }^{1,2}$ and Michael Krebs ${ }^{1}$ \\ ${ }^{1}$ Division of Endocrinology and Metabolism, Department of Internal Medicine III, Medical University of Vienna, \\ Vienna, Austria \\ ${ }^{2}$ High Field MR Centre, Department of Biomedical Imaging and Image-guided Therapy, Medical \\ University of Vienna, Vienna, Austria
}

Correspondence

should be addressed

to $\mathrm{M}$ Krebs

Email

michael.krebs@meduniwien.

ac.at

\begin{abstract}
Cardiovascular disease is the leading cause of death in general population. Besides well-known risk factors such as hypertension, impaired glucose tolerance and dyslipidemia, growing evidence suggests that hormonal changes in various endocrine diseases also impact the cardiac morphology and function. Recent studies highlight the importance of ectopic intracellular myocardial and pericardial lipid deposition, since even slight changes of these fat depots are associated with alterations in cardiac performance. In this review, we overview the effects of hormones, including insulin, thyroid hormones, growth hormone and cortisol, on heart function, focusing on their impact on myocardial lipid metabolism, cardiac substrate utilization and ectopic lipid deposition, in order to highlight the important role of even subtle hormonal changes for heart function in various endocrine and metabolic diseases.
\end{abstract}
Key Words
- myocardial lipids
- cardiac steatosis
- diabetic cardiomyopathy
- hypothyroidism

\section{Introduction}

Heart failure is one of the leading causes of death in the general population, making it to an important medical and socioeconomic burden (1). In the United States of America, one of nine death certificates mentioned heart failure in 2009. In contrast to the overall rate of death attributable to atherosclerosis and cardiovascular disease (CVD), which is constantly declining within the past 10 years, no improvement could be observed for death from heart failure (2). Furthermore, heart failure with preserved ejection fraction (HFpEF) has been accepted as an own condition, being linked to metabolic rather than atherosclerotic disturbances, further indicating the importance of considering metabolic changes in the development of heart failure.

Besides well-known cardiovascular risk factors including hypertension, dyslipidemia, smoking and impaired glucose tolerance, all promoting development of atherosclerosis, there is growing evidence suggesting that hormonal changes in various endocrine diseases also impact the cardiac morphology and function. We and others have demonstrated the importance of a well-balanced hormonal and metabolic homeostasis to maintain myocardial energy metabolism so that heart function can adapt adequately to situations of increased cardiac stress.

In this review, we aim to overview the influence of hormones on heart function, focusing on their impact on myocardial lipid metabolism, cardiac substrate utilization and ectopic lipid deposition, in order to highlight the important role of even subtle hormonal changes for heart function in various endocrine and metabolic diseases.

\section{Myocardial energy metabolism under physiological conditions}

The human heart is the most energy-per-mass consuming organ in the whole body; approximately $6 \mathrm{~kg}$ of ATP, which is about twenty times its own weight, are cycled in the myocardium every day (3). Under physiological conditions, the heart is considered as a metabolic omnivore, generating its energy from lipids, glucose, amino acids, ketone bodies and lactate, depending on the availability and demand (4). Nevertheless, most of 
the energy used by the myocardium is derived from betaoxidation of fatty acids (FAs). FA uptake by the heart is primarily determined by circulating levels of plasma free FA that enter the myocardium by passive diffusion and by active FA transport proteins (5). In the resting state, approximately $70-90 \%$ of FA entering cardiomyocytes are rapidly used for ATP synthesis (6), whereas only 10-30\% of FA are stored in the intracellular myocardial lipid (MYCL) pool. MYCL can be used as a readily available source of energy and are conversely related to circulating levels of free FA (7).

Only $10-40 \%$ of cardiac energy demands is covered by pyruvate oxidation derived from glycolysis and lactate oxidation under physiological conditions (8). Glucose transport into the myocardium is mediated by glucose transporters (GLUT), mainly GLUT-4 and to a lesser extent GLUT-1. Expression of GLUT-4 is stimulated by insulin and activation of AMP-activated protein kinase (AMPK) due to cardiac stress (9). Similar to free FA, an overload of carbohydrates can be stored as glycogen in the myocardium, but glycogen stores in the heart are rather small, compared to that in skeletal muscle (10), indicating that intracellular lipid stores might play more important role in states of increased energy demands.

As reported by Randle and coworkers in the early 1960s, fluxes of FA and glucose strongly interact with each other. Competition between free FA and glucose as substrates for mitochondrial oxidation in skeletal muscle $(11,12)$ was observed. This is also true for the myocardium, where the rate of FA oxidation is the main regulator of glycolysis and vice versa (5).

With regard to cardiac lipid storage, MYCL presents an important substrate pool to maintain energy metabolism in conditions of increased need in cardiac stress (5). Additionally, energy turnover and metabolism of MYCL is very flexible and can rapidly adapt to changes in circulating substrates. Depending on the duration and severity of caloric restriction, elevated circulating levels of FA concentration during prolonged fasting induces an increase in MYCL (13), whereas the decline in plasma FA after pharmacological inhibition of adipose tissue lipolysis was accompanied by an approximate 50\% decrease of MYCL content in young, lean, insulin sensitive subjects (14). These changes in intracellular lipid stores are associated with altered heart function, since increased MYCL stores were linked to decreased left ventricular (LV) diastolic function during prolonged starvation (13) and acutely decreased MYCL content was accompanied by a reduction in systolic LV heart function (14).
Tracer studies demonstrated approximately 80\% decreased uptake of free FA into cardiomyocytes after the inhibition of adipose tissue lipolysis, followed by a six-fold increased glucose uptake that compensates for the lack of energy due to the reduced beta oxidation (15). However, these adaptive changes seem to be insufficient to acutely cope with cardiac energy requirements, since they are associated with decreased cardiac output.

Besides, also under the suppression of circulating levels of free FA by combined hyperglycemia and hyperinsulinemia, MYCL increases (16), most likely due to direct insulin-stimulated inhibition of lipid oxidation (17) or due to the competition with increased intramyocardial glucose supply.

Nowadays, MYCL can be measured non-invasively in vivo in humans by using $1 \mathrm{H}$ magnetic resonance spectroscopy $\left({ }^{1} \mathrm{H}\right.$ MRS) as shown in Fig. 1. This allows repetitive measurements in subjects to assess effects of individual treatment and to track alterations in MYCL following controlled changes in circulating hormone concentrations.

\section{Cardiac steatosis and left ventricular heart function}

Despite the importance of MYCL storage for the maintenance of heart function in situations of increased cardiac energy demand and quick adaption to fluctuating concentrations of circulating substrates, excessive ectopic lipid deposition results in cardiac steatosis followed by fibrosis and LV diastolic dysfunction due to glucolipotoxicity (18). Because of an imbalance in substrate uptake and availability to the cell and substrate oxidation in the cell, there is an accumulation of non-oxidative intermediates of FA metabolism in the cardiomyocytes, resulting in cardiac steatosis (19). Accumulation of toxic lipid intermediates, particularly diacylglycerol and ceramides, induces oxidative stress, increases production of reactive oxygen species (ROS) and results in oxidative damage of cellular membrane integrity, organelle dysfunction and dysregulation of gene expression (20). Animal models impressively demonstrate the importance of a well-balanced interplay between lipid storage and lipolysis in cardiomyocytes, since mice lacking adipose triglyceride lipase (ATGL) develop extreme forms of cardiac steatosis, myocardial hypertrophy and die early from LV heart failure (21). 


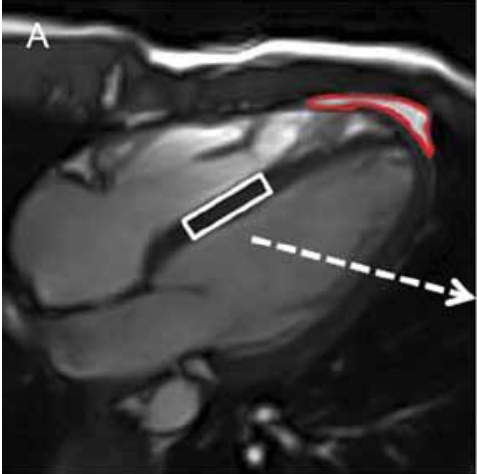

D
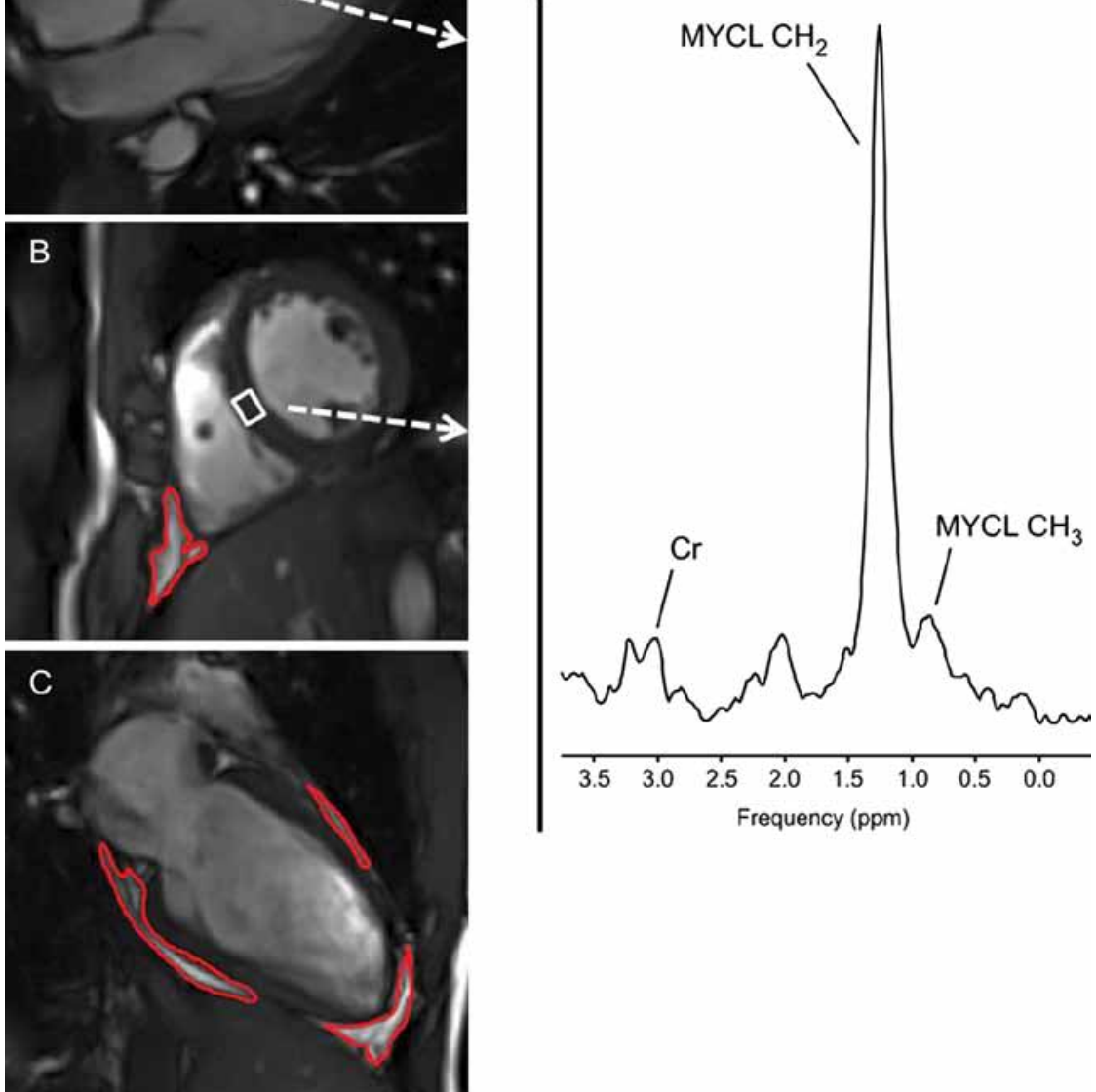

Figure 1

${ }^{1} \mathrm{H}$ MRI and MRS of heart - Cardiac $\mathrm{T}_{1}$-weighted four chambers (A), short axis (B) and two chambers (C) MR images acquired at the end of diastole. Blood and fat tissues show hyperintense (bright). Red contours depict the segmentation of pericardial fat. White boxes within the septum depict the position of volume of interest (VOI) from which ${ }^{1} H$ MRS (D) is acquired. Spectral lines of methylene $\left(\mathrm{MYCL}-\mathrm{CH}_{2}\right.$ ) and methyl ( $\mathrm{MYCL}$ $\mathrm{CH}_{3}$ ) groups of myocardial lipids as well as the line of creatine $(\mathrm{Cr})$ are annotated.

In humans, increased MYCL deposition and cardiac steatosis is independently associated with impaired LV diastolic heart function in patients suffering from type 2 diabetes mellitus (T2DM) $(22,23)$. Furthermore, even in the absence of comorbidities such as hyperglycemia and dyslipidemia, obesity is related to ectopic lipid accumulation in the heart and diastolic dysfunction (24, 25). Additionally, MYCL is increased in elderly men and closely correlates with the age-related decline in diastolic heart function (26).

Additionally, not only MYCL, but also pericardial fat might be important in the development of heart failure. In metabolically healthy subjects, pericardial fat, but not MYCL, is associated with LV systolic function. Stroke volume and cardiac output both correlated significantly with pericardial fat, whereas no relationship with MYCL could be found (27). In addition, increased epicardial and pericardial fat is linked with changes in heart function in men suffering from metabolic syndrome (28), as well as in obese patients suffering from insulin resistance (29). Of note, MYCL and pericardial fat are two lipid stores of completely different origin, since pericardial fat reflects thoracic visceral obesity, but not ectopic intracellular lipid accumulation (Fig. 1).

Finally, it is important to emphasize that ectopic fat as such does not inevitably relate to impaired energy metabolism, but that it plays a role in substrate delivery during conditions of increased energy demands either. This is highlighted by the athlete's paradox in skeletal muscle, since ectopic lipids are similarly high in patients with T2DM and endurance-trained athletes and are elevated compared to that in lean controls (30). Of note, metabolic features of fat mass in skeletal muscle were completely different between the groups of patients with

$$
\begin{array}{lr}
\text { http://www.endocrineconnections.org } & \odot 2017 \text { The authors } \\
\text { DOI: } 10.1530 / \text { EC-17-0031 } & \text { Published by Bioscientifica Ltd }
\end{array}
$$

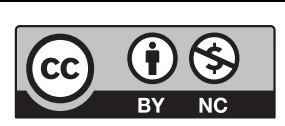


T2DM and athletes, since in insulin sensitive trained subjects no association between insulin sensitivity and amount of lipids was observed (30).

There are some hypotheses trying to explain the athlete's paradox. One might be individual cellular oxidative capacity and mitochondrial activity. Studies on offsprings of patients suffering from T2DM showed that impaired mitochondrial activity might be one of the initial defects in the development of insulin resistance. Whether lipids accumulate in ectopic fat depots, where they exert lipotoxic effects, or whether they are used immediately as substrates for lipid oxidation in cases of increased energy demand, might be mediated by mitochondrial activity $(31,32)$.

Another factor contributing to the athlete's paradox might be the availability of acetylcarnitine and the role of carnitine metabolism in fatty acid oxidation. Recent studies using ${ }^{1} \mathrm{H}$ MR spectroscopy elegantly demonstrated a tight relationship between acetylcarnitine concentration and insulin sensitivity. Additionally, endurance trained athletes had significantly higher formation of acetylcarnitine compared to patients with T2DM, despite similar ectopic fat mass $(33,34)$. However, it has to be established if these changes in carnitine metabolism are cause or consequence of impaired insulin action and insulin resistance.

Based on this evidence, it is important to emphasize the crucial interplay between cardiac morphology, cardiac energy metabolism and cardiac function, since all these three parts of the human heart actively influence each other under physiological conditions, as well as in various metabolic and endocrine diseases. However, up to now no proof of a clear direct causal role of MYCL in heart failure exists and interventional studies showing benefits following reduction of MYCL are missing.

\section{Insulin}

Most data and evidence on the important role of hormones for cardiac energy metabolism are on insulin. The dramatically growing incidence of T2DM in industrialized countries is accompanied by an increase in diabetic cardiomyopathy (CMP), which is characterized by impaired LV function in the absence of coronary artery disease or hypertension and cardiac steatosis is an important player in its development (extensively reviewed in $(35,36,37,38,39))$. Effects of insulin on MYCL are in parts due to its action on FA and regulation of lipolysis and intracellular triglyceride synthesis. However, in the absence of circulating FA, an increase in insulin levels due to hyperglycemia induced by a constant glucose infusion significantly increased MYCL in healthy subjects (16). These changes were accompanied by a marked increase in systolic LV function, since insulin is a potent activator of sympathetic nervous system $(40,41)$.

Similarly, initial phase (10 days) of intensive insulin therapy in patients suffering from T2DM inadequately controlled by oral glucose lowering therapy lead to the rise in MYCL and a significant rise in myocardial mass by approximately $80 \%$ (42). This is most likely mediated by increased myocardial glucose uptake due to promoted translocation of GLUT4, inducing a switch in substrate utilization from FA to glucose. This pathway is regulated mainly by malonyl-CoA, which is generated by acetyl-CoA carboxylase (ACC) and inhibits carnitine palmitoyltransferase-1 (CPT-1) (17). CPT-1 controls the rate-limiting step of mitochondrial FA uptake and oxidation. Additionally, insulin exerts a direct stimulatory effect on ACC and thereby potently suppresses mitochondrial lipid oxidation in the presence of hyperglycemia, promoting ectopic lipid deposition in the heart (18). Similar effects following insulin administration could be observed in other insulindependent organs, since initiation of constant insulin infusion and normoglycemia lead to significant increases in ectopic lipid deposition in skeletal muscle and in the liver of patients suffering from T2DM (43).

Interestingly, insulin resistance as such is not associated with increased MYCL deposition (44), which stands in sharp contrast to the liver (45) and skeletal muscle (46). Therefore, insulin resistance is not causal for ectopic fat accumulation in the heart, but cardiac steatosis in T2DM might represent a final stage after long-standing derangement of glucose and lipid metabolism. In contrast to the myocardium, impaired action of insulin to regulate glucose and lipid homeostasis in the liver and skeletal muscle and ectopic lipid deposition in these organs present the initial steps in the development of insulin resistance. This interorgan crosstalk between the liver, skeletal muscle, adipose tissue and the heart, as well as different steps in the development of cardiac steatosis on the background of insulin resistance and substrate FA availability are illustrated in Fig. 2. http://www.endocrineconnections.org DOI: 10.1530/EC-17-0031
(C) 2017 The authors Published by Bioscientifica Ltd
This work is licensed under a Creative Commons Attribution-NonCommercial 4.0 International License. 


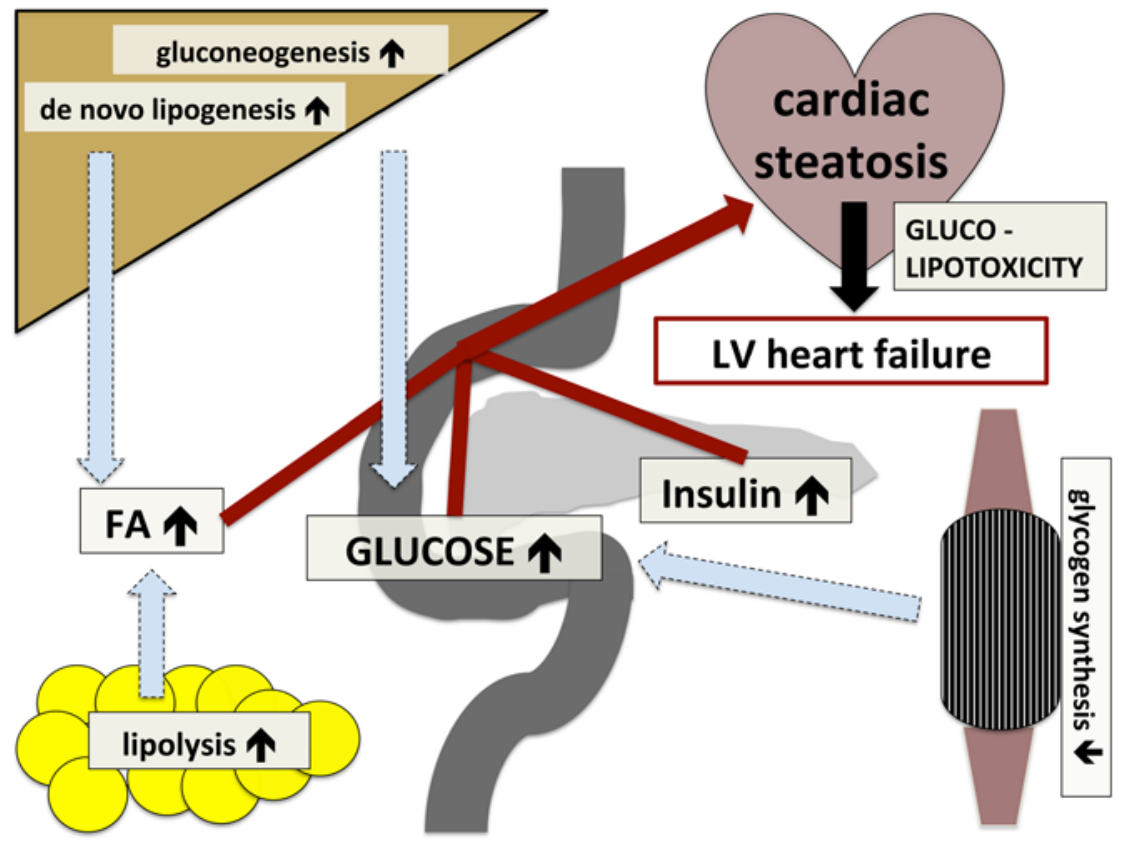

\begin{abstract}
Figure 2
Inter-organ crosstalk in the development of cardiac steatosis and left ventricular (LV) heart failure on the background of insulin resistance. Decreased insulin sensitivity leads to $(A)$ impaired glycogen synthesis in skeletal muscle, promoting hyperglycemia; (B) unrestrained hepatic lipogenesis and gluconeogenesis, promoting hyperglycemia and dyslipidemia; and (C) augmented lipolysis in adipose tissue, promoting dyslipidemia; increased concentrations of insulin, glucose and free fatty acids (FAs) results in increased lipid accumulation in the myocardium and cardiac glucolipotoxicity, which ends up in LV heart failure.
\end{abstract}

\section{Thyroid hormones}

Thyroid hormones exert effects virtually on every organ system, including the heart. Cohort studies based on large population impressively emphasize on the relationship between disturbances in thyroid function and a greater risk of clinical manifestation of heart failure in patients with thyroid stimulating hormone (TSH) $<0.1$ or $\geq 10 \mu \mathrm{U} /$ $\mathrm{mL}$ (47). Especially in patients suffering from congestive heart failure, both subclinical hypothyroidism and overt hypothyroidism are associated with increased mortality (48). The same is true for patients hospitalized for acutely decompensated heart failure, in which subclinical hypothyroidism, but not subclinical hyperthyroidism independently predicts adverse cardiovascular outcomes, including cardiac death and re-hospitalization for heart failure (49). Hemodynamic changes in hypothyroid patients include bradycardiac heart rate and therefore reduced cardiac output, increased vascular resistance and reduced diastolic filling rates (50). Even in patients suffering from only subclinical hypothyroidism parameters of $\mathrm{LV}$ diastolic function are impaired and tend to normalize compared to matched euthyroid controls 6 months after adequate thyroid hormone replacement therapy (51).

Hypothyroidism is linked to alterations of lipid metabolism. This includes elevations in low-density lipoprotein (LDL) cholesterol, as well as decreased highdensity lipoprotein (HDL) cholesterol levels, which tend to normalize following thyroxin supplementation (52). These changes are due to important effects of thyroid hormone on several key enzymes of lipid metabolism (53) and result in a significantly increased risk for cardiovascular diseases in hypothyroid patients (54).

Thyroid hormones stimulate energy expenditure by promoting mitochondrial uncoupling and inducing thermogenesis in humans (55). Additionally, animal models nicely demonstrate that tri-iodothyronine (T3) directly acts on free FA uptake and oxidation in the myocardium (56). Decreased rates of whole-body energy metabolism in hypothyroid state result in reduced lipid oxidation, despite unaltered adipose tissue lipolysis (57).

The combination of increased substrate supply through elevated circulating levels of lipids and decreased lipid oxidation could be linked to decreased MYCL stores in patients suffering from overt hypothyroidism by approximately $30 \%$, 4 weeks after total thyroidectomy for differentiated thyroid cancer, when thyroid function was adequately substituted. These changes in ectopic fat accumulation were accompanied by a significant improvement of cardiac output (58).

Interestingly, also cardiac bioenergetics estimated by the rate of ATP synthesis from phosphocreatine was different even in subclinical hypothyroidism and improved with therapy, approaching matched controls (59). Effects on ATP synthesis might be secondary to cardiac steatosis, probably mediated by cardiac lipotoxicity, since at least in skeletal muscle thyroid hormones were shown
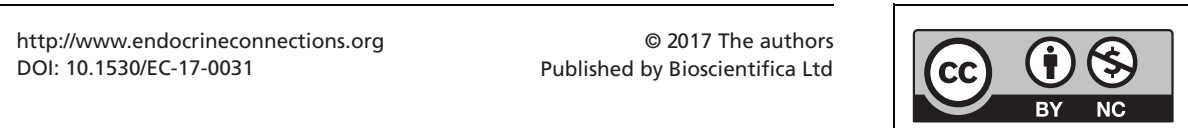

This work is licensed under a Creative Commons Attribution-NonCommercial 4.0 International License. 
not to directly increase ATP synthesis, but drive energy turnover by mitochondrial uncoupling and increased thermogenesis (55).

Therefore, similar to diabetic CMP, also in hypothyroid subjects impaired lipid metabolism and mitochondrial dysfunction within the heart might play an important role for the development of disease-specific heart failure. Thus, thyroid function should be assessed in subjects with cardiovascular and metabolic diseases, although data of large long-term prospective studies on the impact and benefit of thyroid hormone replacement therapy are conflicting (60).

Moreover, hyperthyroidism and activation of the sympathetic nervous system share many cardiostimulatory effects including tachycardia and increased contractility resulting in an increase in metabolic demand. Recent evidence suggests that 3-iodothyronamine, which is a decarboxylated derivative of T4, modulates activation of alpha-2A-adrenergic receptors by norepinehprine (61). Additionally, various components of the beta-adrenergic receptor are modulated by thyroid hormone activity (50). However, studies on betaadrenergic receptor knock out mice could not confirm differences of thyroid hormone action compared to that in wild-type mice (62). Therefore, thyroid hormones might exert their effects on the heart also independently of adrenergic stimuli.

\section{Growth hormone}

Metabolic disturbances in patients suffering from excessive production of growth hormone $(\mathrm{GH})$, termed acromegaly, seem to be similar to those in the insulin resistant state, i.e. hyperglycemia, hyperinsulinemia and hypertriglyceridemia (63). Conversely, untreated GH deficiency is also closely related to multiple features of the metabolic syndrome, including visceral obesity, hypertension and dyslipidemia (64).

Recent evidence suggests that biological effects of $\mathrm{GH}$ on substrate metabolism through direct or indirect stimulation of production of insulin-like growth factor1 (IGF-1) are complex. GH is directly acting as a strong promoter in lipolytic signaling (65). In contrast, GH might also promote lipid synthesis and storage by induction of IGF-1, which stimulates the insulin-signaling pathway (66).

In adipose tissue, $\mathrm{GH}$ is an important mediator of lipolysis and directly acts on hormone sensitive lipase and enhances the responsiveness for beta-adrenergic activity, which might explain higher plasma TG concentrations, observed in patients with acromegaly (63).

Besides these metabolic effects counteracting insulin action and promoting the development of insulin resistance, GH and IGF-1 are both reported to increase mitochondrial oxidation capacity in animal models, as well as in humans and therefore promote wholebody energy expenditure. The hepatic fat content and plasma lipid concentration decreased significantly after supplementation of GH in GH-deficient mice, secondary to improved mitochondrial function and reduced oxidative stress (67). In young healthy subjects, overnight infusion of GH promotes mitochondrial ATP production in skeletal muscle (68) and GH- deficient subjects exhibit an increase in lipid oxidation rates after supplementation of GH (69).

Besides these effects that contribute to a proatherosclerotic background in $\mathrm{GH}$ excess and $\mathrm{GH}$ deficiency and therefore passively promote the development of cardiovascular disease, cardiomyocytes directly express receptors for GH and IGF-1. Stimulation of these receptors induces cardiac hypertrophy and affects cardiac contractility (70).

Based on this background, it is of considerable interest that ectopic lipid deposition in insulin-sensitive organs (liver, heart) was lower in patients suffering from active acromegaly compared to well-matched healthy controls. Notably, hepatic lipid content was substantially lower in patients with acromegaly, who suffered from severe insulin resistance or even T2DM, compared to metabolically healthy controls. Moreover, MYCL stores were reduced in acromegaly and tended to reach statistical significance $(P=0.053)$ compared to the control group. Therefore, GH excess presents a unique condition of low ectopic lipid content, despite hyperlipidemia, hyperinsulinemia and hyperglycemia (71).

It remains to be investigated whether this is due to increased lipid oxidation promoted by GH and IGF-1 or due to alterations in hepatic lipid metabolism, i.e. de novo lipogenesis and lipolysis.

With regard to cardiac morphology, LV myocardial mass, wall thickness and LV end-diastolic volume was significantly greater in active acromegaly compared to healthy controls and significantly decreased tending towards normal values in a short-term follow-up for about 6 months after the cure of GH excess by pituitary surgery (71). However, these alterations were not related with metabolic alterations or increased ectopic lipid accumulation, which stands in contrast to observed 
changes in morphology of the heart in patients suffering from T2DM and hypothyroidism.

\section{Cortisol}

Death from cardiovascular disease, including heart failure, coronary artery disease and cardiac thromboembolism, is the leading cause of increased mortality observed in patients suffering from Cushing's syndrome. Even in long-term follow-up many years after complete cure of hypercortisolism, cardiovascular risk is still increased (72). In parts, increased cardiovascular mortality is mediated due to common metabolic risk factors of atherosclerosis, including visceral obesity, hypertension, dyslipidemia and insulin resistance or even T2DM. Data of cross-sectional studies indicate that more than two of three patients suffering from Cushing's syndrome have at least three of these metabolic derangements and therefore fulfill the criteria of metabolic syndrome (73). These risk factors are still significantly elevated 1 and 5 years after the successful cure of hypercortisolism, accompanied by increased prevalence of atherosclerotic plaques, reduced caliber and increased stiffness of the carotid artery assessed by echoDoppler ultrasonography $(74,75)$.

Besides these metabolic complications described above, which accelerate the development of atherosclerosis and coronary artery disease, also cardiac morphology and function is altered in Cushing's syndrome, tending to normalize after correction of hypercortisolism (76). In case control studies of patients with Cushing's syndrome, the prevalence of LV hypertrophy assessed by echocardiography was about $70 \%$. Interestingly, these changes were independent from hypertension and dyslipidemia, since no difference could be found compared to matched controls (77). Abnormalities in LV morphology are associated with a decrease of mid LV systolic function and alterations of diastolic filling (78). These echo-based findings were recently confirmed by studies using cardiac magnetic resonance tomography, where LV mass was significantly increased in patients suffering from Cushing's syndrome and reduced by $17 \%$ in a follow-up investigation 6 months after the treatment. Interestingly, also LV systolic function as assed by ejection fraction improved significantly after the therapy (76).

Of note, it is unclear why there is hypertrophy of cardiomyocytes, despite the background of generalized muscular atrophy observed in hypercortisolism due to enhanced protein catabolism. Glucocorticoid receptors are expressed in the heart $(79,80)$, therefore excess of cortisol might exert direct effects on myocardial tissue. Additionally, cortisol potentiates action of catecholamines and the renin-angiotensin system in the heart and might indirectly mediate cardiac toxicity (78).

On the background of several metabolic comorbidities in Cushing's disease including dyslipidemia and the high prevalence of T2DM, it is tempting to speculate about glucolipotoxic effects on the heart, although no data on ectopic lipid accumulation in the heart in endogenous hypercortisolism is available. At least in skeletal muscle, short-term hypercortisolism by oral hydrocortisone administration for 28 days almost doubled intramuscular triglyceride concentrations and significantly worsened insulin sensitivity (81), although effects observed in this study cannot be attributed only to hypercortisolism, since subjects had to concomitantly adhere to strict physical inactivity. Additionally, hepatic steatosis is common in patients with Cushing's disease (82). Fatty liver disease was shown to affect myocardial energy metabolism in young non-diabetic men (83). In patients suffering from hepatic steatosis and T2DM, signs of LV diastolic function could be detected earlier compared to patients suffering from only T2DM (84).

We suggest that adverse metabolic effects of ectopic fat accumulation in insulin-sensitive organs including the heart are also present in overt hypercortisolism. However, studies testing this hypothesis as well as studies on MYCL in Cushing's disease are not available yet.

\section{Conclusions and outlook}

Subtle subclinical and overt endocrine diseases affect cardiac fat depots in many ways (Table 1). Excess hormone in various endocrine diseases results in altered myocardial lipid accumulation and energy metabolism, which might result in disease-specific cardiomyopathy. These alterations in ectopic lipid load of the myocardium might be in parts secondary to dyslipidemia, commonly

Table 1 Effects of insulin, thyroid hormones, growth hormone and cortisol on the human heart.

\begin{tabular}{|c|c|c|c|}
\hline & MYCL & LVF & Hypertrophy \\
\hline Insulin & + & + & + \\
\hline Growth hormone & - & $?$ & ++ \\
\hline Thyroid hormones & - & + & $?$ \\
\hline Cortisol & $?$ & - & ++ \\
\hline
\end{tabular}

MYCL, intramyocardial lipid content; LVF, left ventricular function; +, promoting effect; ++, strong promoting effect; ?, unknown effect; - , reducing effect. 
present in insulin resistance, hypothyroid state or hypercortisolism, but are also observed in the absence of elevated circulating levels of free FA. There is a reduction in ectopic lipid content despite elevated circulating levels of lipid in GH excess, highlighting the potency of hormonal action itself.

However, long-term prospective cohort studies on the effects of changes in cardiac lipids on cardiovascular morbidity and mortality are missing. Furthermore, it cannot be concluded if excessive MYCL as such is causally related to cardiomyopathy in endocrine disease or if alterations in fat depots of the heart are secondary failures.

Another question to be addressed in the future is if novel drug approaches for metabolic diseases, such as sodium-glucose-transporter-2 (SGLT-2) inhibitors or glucagon-like-peptide-1 (GLP-1) analogs that improve cardiovascular outcome in patients suffering from T2DM $(85,86)$, exert parts of their beneficial effects by affecting cardiac lipid deposition.

In general, changes in cardiac fat, function and morphology might be used as an important outcome parameter in the assessment of excess hormone and individual treatment response, since they are highly sensitive and differences can be observed within a short period.

\section{Declaration of interest}

M Kre. has received research support from Sanofi and AstraZeneca as well as speaker and consulting fees from AstraZeneca, Novartis, Novo Nordisk, Lilly and Sanofi. P W, Y W and M Krs have no conflict of interest that could be perceived as prejudicing the impartiality of this review.

\section{Funding}

This work was supported by grants from the Austrian Association of Endocrinology and Metabolism (ÖGES) to P W and $\mathrm{Y} W$ as well as the Austrian Heart Foundation and the Medical Scientific Fund of the Mayor of the City of Vienna (Grant 12023), both to M.Kre. and by the Austrian National Bank (Nr. 13249 and 15363) to M Krs.

\section{Author contribution}

All authors contributed equally in writing the manuscript.

\section{References}

1 Bhatnagar P, Wickramasinghe K, Wilkins E \& Townsend N. Trends in the epidemiology of cardiovascular disease in the UK. Heart $2016 \mathbf{1 0 2}$ 1945-1952. (doi:10.1136/heartjnl-2016-309573)

2 Go AS, Mozaffarian D, Roger VL, Benjamin EJ, Berry JD, Borden WB, Bravata DM, Dai S, Ford ES, Fox CS, et al. Executive summary: heart disease and stroke statistics - 2013 update: a report from the american heart association. Circulation 2013127 143-152. (doi:10.1161/ CIR.0b013e318282ab8f)

3 Neubauer S. The failing heart - an engine out of fuel. New England Journal of Medicine 2007356 1140-1151. (doi:10.1056/NEJMra063052)
4 Bayeva M, Sawicki KT \& Ardehali H. Taking diabetes to heart - deregulation of myocardial lipid metabolism in diabetic cardiomyopathy. Journal of the American Heart Association 20132 e000433. (doi:10.1161/JAHA.113.000433)

5 Stanley WC, Recchia FA \& Lopaschuk GD. Myocardial substrate metabolism in the normal and failing heart. Physiological Reviews 2005 85 1093-1129. (doi:10.1152/physrev.00006.2004)

6 Wisneski J, Gertz E, Neese R \& Mayr M. Myocardial metabolism of free fatty acids. Journal of Clinical Investigations 198779 359-366. (doi:10.1172/JCI112820)

7 Saddik M \& Lopaschuk GD. Myocardial triglyceride turnover and contribution to energy substrate utilization in isolated working rat hearts. Journal of Biological Chemistry 1991266 8162-8170.

8 Wisneski J, Gertz E, Neese R, Gruenke L, Morris L \& Craig C. Metabolic fate of extracted glucose in normal human myocardium. Journal of Clinical Investigation 198576 1819-1827. (doi:10.1172/ JCI112174)

9 Young L, Coven D \& Russel R. Cellular and molecular regulation of cardiac glucose transport. Journal of Nuclear Cardiolgoy 20007 267-276. (doi:10.1016/S1071-3581(00)70016-X)

10 Botker HE, Helligso P, Kimose H, Thomassen A \& Nielsen T. Determination of high energy phosphates and glycogen in cardiac and skeletal muscle biopsies, with special reference to influence of biopsy technique and delayed freezing. Cardiovascular Research 1994 28 524-527. (doi:10.1093/cvr/28.4.524)

11 Randle PJ, Garland PB, Hales CN \& Newsholme EA. The glucose fatty-acid cycle. Its role in insulin sensitivity and the metabolic disturbances of diabetes mellitus. Lancet 19631 785-789. (doi:10.1016/S0140-6736(63)91500-9)

12 Randle PJ, Garland PB, Newsholme EA \& Hales CN. The glucose fatty acid cycle in obesity and maturity onset diabetes mellitus. Annals of the New York Academy of Science 1965131 324-333. (doi:10.1111/j.1749-6632.1965.tb34800.x)

13 Hammer S, van der Meer RW, Lamb HJ, Schar M, de Roos A, Smit JW \& Romijn JA. Progressive caloric restriction induces dose-dependent changes in myocardial triglyceride content and diastolic function in healthy men. Journal of Clinical Endocrinology and Metabolism 200893 497-503. (doi:10.1210/jc.2007-2015)

14 Winhofer Y, Krssak M, Wolf P, Anderwald CH, Geroldinger A, Heinze G, Baumgartner-Parzer S, Marculescu R, Stulnig T, Wolzt M, et al. Free fatty acid availability is closely related to myocardial lipid storage and cardiac function in hypoglycemia counter-regulation. American Journal of Physiology: Endocrinology and Metabolism 2015308 E631-E640, ajpendo 0037102014 . (doi:10.1152/ajpendo.00371.2014)

15 Tuunanen H, Engblom E, Naum A, Någren K, Hesse B, Airaksinen KEJ, Nuutila P, Iozzo P, Ukkonen H, Opie LH, et al. Free fatty acid depletion acutely decreases cardiac work and efficiency in cardiomyopathic heart failure. Circulation 2006114 2130-2137. (doi:10.1161/ CIRCULATIONAHA.106.645184)

16 Winhofer Y, Krssak M, Jankovic D, Anderwald CH, Reiter G, Hofer A, Trattnig S, Luger A \& Krebs M. Short-term hyperinsulinemia and hyperglycemia increase myocardial lipid content in normal subjects. Diabetes 201261 1210-1216. (doi:10.2337/db11-1275)

17 Witters L \& Kemp B. Insulin activation of acetyl-coA carboxylase accompanied by inhibition of the 5 -AMP-activated protein kinase. Journal of Biological Chemistry 1991267 2864-2867.

18 Wolf P, Winhofer Y, Anderwald CH, Krssak M \& Krebs M. Intracellular lipid accumulation and shift during diabetes progression. Wiener Medizinische Wochenschrift 2014164 320-329. (doi:10.1007/s10354014-0292-y)

19 Taegtmeyer H \& Stanley WC. Too much or not enough of a good thing? Cardiac glucolipotoxicity versus lipoprotection. Journal of Molecular and Cellular Cardiology 201150 2-5. (doi:10.1016/j. yjmcc.2010.09.014)

20 Brookheart RT, Michel CI \& Schaffer JE. As a matter of fat. Cell Metabolism 2009 10 9-12. (doi:10.1016/j.cmet.2009.03.011)

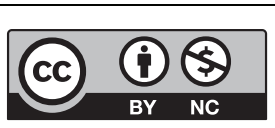


21 Haemmerle G, Lass A, Zimmermann R, Gorkiewicz G, Meyer C, Rozman J, Heldmaier G, Maier R, Theussl C, Eder S, et al. Defective lipolysis and altered energy metabolism in mice lacking adipose triglyceride lipase. Science 2006312 734-737. (doi:10.1126/ science.1123965)

22 Rijzewijk LJ, van der Meer RW, Smit JW, Diamant M, Bax JJ, Hammer S, Romijn JA, de Roos A \& Lamb HJ. Myocardial steatosis is an independent predictor of diastolic dysfunction in type 2 diabetes mellitus. Journal of the American College of Cardiology $2008 \mathbf{5 2}$ 1793-1799. (doi:10.1016/j.jacc.2008.07.062)

23 McGavock JM, Lingvay I, Zib I, Tillery T, Salas N, Unger R, Levine BD, Raskin P, Victor RG \& Szczepaniak LS. Cardiac steatosis in diabetes mellitus: a $1 \mathrm{H}$-magnetic resonance spectroscopy study. Circulation 2007116 1170-1175. (doi:10.1161/ CIRCULATIONAHA.106.645614)

24 Banerjee R, Rial B, Holloway CJ, Lewandowski AJ, Robson MD, Osuchukwu C, Schneider JE, Leeson P, Rider OJ \& Neubauer S. Evidence of a direct effect of myocardial steatosis on LV hypertrophy and diastolic dysfunction in adult and adolescent obesity. JACC: Cardiovascular Imaging 20158 1468-1470. (doi:10.1016/j. jcmg.2014.12.019)

25 Graner M, Siren R, Nyman K, Lundbom J, Hakkarainen A, Pentikainen MO, Lauerma K, Lundbom N, Adiels M, Nieminen MS, et al. Cardiac steatosis associates with visceral obesity in nondiabetic obese men. Journal of Clinical Endocrinology and Metabolism 201398 1189-1197. (doi:10.1210/jc.2012-3190)

26 van der Meer RW, Rijzewijk LJ, Diamant M, Hammer S, Schar M, Bax JJ, Smit JW, Romijn JA, de Roos A \& Lamb HJ. The ageing male heart: myocardial triglyceride content as independent predictor of diastolic function. European Heart Journal 200829 1516-1522. (doi:10.1093/ eurheartj/ehn207)

27 Wolf P, Winhofer Y, Smajis S, Jankovic D, Anderwald CH, Trattnig S, Luger A, Krebs M \& M Krssak. Pericardial - rather than Intramyocardial fat is independently associated with left ventricular systolic heart function in metabolically healthy humans. PLOS ONE 201611 e0151301. (doi:10.1371/journal.pone.0151301)

28 Nyman K, Graner M, Pentikainen MO, Lundbom J, Hakkarainen A, Siren R, Nieminen MS, Taskinen MR, Lundbom J \& Lauerma $\mathrm{K}$. Cardiac steatosis and left ventricular function in men with metabolic syndrome. Journal of Cardiovascular Magnetic Resonance 201315 1-11. (doi:10.1186/1532-429X-15-103)

29 Iacobellis G \& Leonetti F. Epicardial adipose tissue and insulin resistance in obese subjects. Journal of Clinical Endocrinology and Metabolism 200590 6300-6302. (doi:10.1210/jc.2005-1087)

30 Goodpaster BH, He J, Watkins S \& Kelley DE. Skeletal muscle lipid content and insulin resistance evidence for a paradox in endurancetrained athletes. Journal of Clinical Endocrinology and Metabolism 2001 86 5755-5761. (doi:10.1210/jcem.86.12.8075)

31 Petersen KF, Dufour S, Befroy D, Garcia R \& Shulman GI. Impaired mitochondrial activity in the insulin-resistant offspring of patients with type 2 diabetes. New England Journal of Medicine $2004 \mathbf{3 5 0}$ 664-671. (doi:10.1056/NEJMoa031314)

32 Petersen KF, Dufour S \& Shulman GI. Decreased insulin-stimulated ATP synthesis and phosphate transport in muscle of insulin-resistant offspring of type 2 diabetic parents. PLOS Medicine 20052 e233. (doi:10.1371/journal.pmed.0020233)

33 Lindeboom L, Nabuurs CI, Hoeks J, Brouwers B, Phielix E, Kooi ME, Hesselink MK, Wildberger JE, Stevens RD, Koves T, et al. Long-echo time MR spectroscopy for skeletal muscle acetylcarnitine detection. Journal of Clinical Investigation $2014 \mathbf{1 2 4}$ 4915-4925. (doi:10.1172/ JCI74830)

34 Schrauwen P \& van Marken Lichtenbelt WD. Combatting type 2 diabetes by turning up the heat. Diabetologia $2016592269-2279$. (doi:10.1007/s00125-016-4068-3)

35 Bell DSH. Diabetic cardiomyopathy. Diabetes Care 200326 2949-2951. (doi:10.2337/diacare.26.10.2949)
36 Schilling JD \& Mann DL. Diabetic cardiomyopathy: bench to bedside. Heart Failure Clinics 20128 619-631. (doi:10.1016/j.hfc.2012.06.007)

37 Galderisi M. Diastolic dysfunction and diabetic cardiomyopathy: evaluation by Doppler echocardiography. Journal of the American College of Cardiology 200648 1548-1551. (doi:10.1016/j. jacc.2006.07.033)

38 van de Weijer T, Schrauwen-Hinderling VB \& Schrauwen P. Lipotoxicity in type 2 diabetic cardiomyopathy. Cardiovascular Research 201192 10-18. (doi:10.1093/cvr/cvr212)

39 Szczepaniak LS, Victor RG, Orci L \& Unger RH. Forgotten but not gone: the rediscovery of fatty heart, the most common unrecognized disease in America. Circulation Research 2007101 759-767. (doi:10.1161/CIRCRESAHA.107.160457)

40 Landsberg L. Feast or famine: the sympathetic nervous system response to nutrient intake. Cellular and Molecular Neurobiology 2006 26 497-508. (doi:10.1007/s10571-006-9010-7)

41 Rowe J, Young J, Minaker K, Stevens A, Pallota J \& Landsberg L. Effect of insulin and glucose infusions on sympathetitc nervous system activity in normal men. Diabetes 198130 219-225. (doi:10.2337/ diab.30.3.219)

42 Jankovic D, Winhofer Y, Promintzer-Schifferl M, Wohlschlager-Krenn E, Anderwald CH, Wolf P, Scherer T, Reiter G, Trattnig S, Luger A, et al. Effects of insulin therapy on myocardial lipid content and cardiac geometry in patients with type-2 diabetes mellitus. PLOS ONE 20127 e50077. (doi:10.1371/journal.pone.0050077)

43 Anderwald CH, Bernroider E, Krssak M, Stingl H, Brehm A, Bischof M, Nowotny P, Roden M \& Waldhäusl W. Effects of insulin treatment in type 2 diabetic patients on intracellular lipid content in liver and skeletal muscle. Diabetes 200251 3025-3032. (doi:10.2337/ diabetes.51.10.3025)

44 Krššák M, Winhofer Y, Göbl C, Bischof M, Reiter G, Kautzky-Willer A, Luger A, Krebs M \& Anderwald C. Insulin resistance is not associated with myocardial steatosis in women. Diabetologia 201154 1871-1878. (doi:10.1007/s00125-011-2146-0)

45 Fabbrini E, Magkos F, Mohammed BS, Pietka T, Abumrad NA, Patterson BW, Okunade A \& Klein S. Intrahepatic fat, not visceral fat, is linked with metabolic complications of obesity. PNAS 2009106 15430-15435. (doi:10.1073/pnas.0904944106)

46 Krssak M, Petersen KF, Dresner A, DiPietro L, Vogel SM, Rothman DL, Shulman GI \& Roden M. Intramyocellular lipid concentrations are correlated with insulin sensitivity in humans: a 1H NMR spectroscopy study. Diabetologia 199942 113-116. (doi:10.1007/s001250051123)

47 Gencer B, Collet TH, Virgini V, Bauer DC, Gussekloo J, Cappola AR, Nanchen D, den Elzen WP, Balmer P, Luben RN, et al. Subclinical thyroid dysfunction and the risk of heart failure events: an individual participant data analysis from 6 prospective cohorts. Circulation 2012 126 1040-1049. (doi:10.1161/CIRCULATIONAHA.112.096024)

48 Rhee CM, Curhan GC, Alexander EK, Bhan I \& Brunelli SM. Subclinical hypothyroidism and survival: the effects of heart failure and race. Journal of Clinical Endocrinology and Metabolism 201398 2326-2336. (doi:10.1210/jc.2013-1039)

49 Hayashi T, Hasegawa T, Kanzaki H, Funada A, Amaki M, Takahama H, Ohara T, Sugano Y, Yasuda S, Ogawa H, et al. Subclinical hypothyroidism is an independent predictor of adverse cardiovascular outcomes in patients with acute decompensated heart failure. ESC Heart Failure 20163 168-176. (doi:10.1002/ehf2.12084)

50 Klein I \& Ojamaa K. Thyroid hormones and the cardiovascular system. New England Journal of Medicine 2001344 501-509. (doi:10.1056/NEJM200102153440707)

51 Biondi B, Fazio S, Palmieri E, Carella C, Panza N, Cittadini A, Bone F, Lombardi G \& Sacca L. Left ventrivular diastolic dysfunction in patients with subclinical hypothyroidism. Journal of Clinical Endocrinology \& Metabolism 199984 2064-2067. (doi:10.1210/ jc.84.6.2064)

52 Kuusi T, Taskinen MR \& Nikkila E. Lipoproteins, Lipolytic enzymes, and hormonal status in hypothyroid women at different levels of

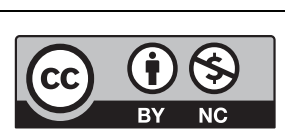

This work is licensed under a Creative Commons Attribution-NonCommercial 4.0 International License. 
substitution. Journal of Clinical Endocrinology \& Metabolism 198866 51-56. (doi:10.1210/jcem-66-1-51)

53 Kahaly GJ \& Dillmann WH. Thyroid hormone action in the heart. Endocrine Reviews 200526 704-728. (doi:10.1210/er.2003-0033)

54 Hak A, Pols H, Visser T, Drexhage H, Hofman A \& Witteman J. Low thyroid function without symptoms as a risk indicator for heart disease in older women. Annals of Internal Medicine 2000132 270-270. (doi:10.7326/0003-4819-132-4-200002150-00004)

55 Lebon V, Dufour S, Petersen KF, Ren J, Jucker BM, Slezak LA, Cline GW, Rothman DL \& Shulman GI. Effect of triiodothyronine on mitochondrial energy coupling in human skeletal muscle. Journal of Clinical Investigation 2001108 733-737. (doi:10.1172/JCI200111775)

56 Krueger J, Ning X, Argo B, Hyyti O \& Portman M. Triiodothyronine and epinephrine rapidly modify myocardial substrate selection: a 13C isotopomer analysis. American Journal of Physiology: Endocrinology and Metabolism 2001281 983-990.

57 Gjedde S, Gormsen LC, Rungby J, Nielsen S, Jorgensen JO, Pedersen SB, Riis AL, Weeke J \& Moller N. Decreased lipid intermediate levels and lipid oxidation rates despite normal lipolysis in patients with hypothyroidism. Thyroid 201020 843-849. (doi:10.1089/ thy.2009.0212)

58 Scherer T, Wolf P, Winhofer Y, Duan H, Einwallner E, Gessl A, Luger A, Trattnig S, Hoffmann M, Niessner A, et al. Levothyroxine replacement in hypothyroid humans reduces myocardial lipid load and improves cardiac function. Journal of Clinical Endocrinology and Metabolism 2014 99 E2341-2346. (doi:10.1210/jc.2014-2112)

59 Madathil A, Hollingsworth KG, Blamire AM, Razvi S, Newton JL, Taylor R \& Weaver JU. Levothyroxine improves abnormal cardiac bioenergetics in subclinical hypothyroidism: a cardiac magnetic resonance spectroscopic study. Journal of Clinical Endocrinology and Metabolism 2015100 E607-E610. (doi:10.1210/jc.2014-2942)

60 Floriani C, Gencer B, Collet TH \& Rodondi N. Subclinical thyroid dysfunction and cardiovascular diseases: 2016 update. European Heart Journal 2017 article ehx050. (doi:10.1093/eurheartj/ehx050)

61 Dinter J, Muhlhaus J, Jacobi SF, Wienchol CL, Coster M, Meister J, Hoefig CS, Muller A, Kohrle J, Gruters A, et al. 3-Iodothyronamine differentially modulates alpha-2A-adrenergic receptor-mediated signaling. Journal of Molecular Endocrinology 201554 205-216. (doi:10.1530/JME-15-0003)

62 Bachman ES, Hampton TG, Dhillon H, Amende I, Wang J, Morgan JP \& Hollenberg AN. The metabolic and cardiovascular effects of hyperthyroidism are largely independent of beta-adrenergic stimulation. Endocrinology 2004145 2767-2774. (doi:10.1210/ en.2003-1670)

63 Colao A, Ferone D, Marzullo P \& Lombardi G. Systemic complications of acromegaly: epidemiology, pathogenesis, and management. Endocrine Reviews 200425 102-152. (doi:10.1210/er.2002-0022)

64 Gardner CJ, Irwin AJ, Daousi C, McFarlane IA, Joseph F, Bell JD, Thomas EL, Adams VL, Kemp GJ \& Cuthbertson DJ. Hepatic steatosis, GH deficiency and the effects of GH replacement: a Liverpool magnetic resonance spectroscopy study. European Journal of Endocrinology 2012166 993-1002. (doi:10.1530/EJE-12-0002)

65 Zechner R, Zimmermann R, Eichmann TO, Kohlwein SD, Haemmerle G, Lass A \& Madeo F. FAT SIGNALS - lipases and lipolysis in lipid metabolism and signaling. Cell Metabolism 201215 279-291. (doi:10.1016/j.cmet.2011.12.018)

66 Saltiel AR \& Kahn CR. Insulin signalling and the regulatino of glucose and lipid metabolism. Nature 2001414 799-806. (doi:10.1038/414799a)

67 Nishizawa H, Takahashi M, Fukuoka H, Iguchi G, Kitazawa R \& Takahashi Y. GH-independent IGF-I action is essential to prevent the development of nonalcoholic steatohepatitis in a GH-deficient rat model. Biochemical and Biophysical Research Communications 2012423 295-300. (doi:10.1016/j.bbrc.2012.05.115)

68 Short KR, Moller N, Bigelow ML, Coenen-Schimke J \& Nair KS. Enhancement of muscle mitochondrial function by growth hormone.
Journal of Clinical Endocrinology and Metabolism 200893 597-604. (doi:10.1210/jc.2007-1814)

69 Sjogren K, Leung KC, Kaplan W, Gardiner-Garden M, Gibney J \& Ho KK. Growth hormone regulation of metabolic gene expression in muscle: a microarray study in hypopituitary men. American Journal of Physiology: Endocrinology and Metabolism 2007293 E364-E371. (doi:10.1152/ajpendo.00054.2007)

70 Colao A. The GH-IGF-I axis and the cardiovascular system: clinical implications. Clinical Endocrinology 200869 347-358. (doi:10.1111/ j.1365-2265.2008.03292.x)

71 Winhofer Y, Wolf P, Krssak M, Wolfsberger S, Tura A, Pacini G, Gessl A, Raber W, Kukurova IJ, Kautzky-Willer A, et al. No evidence of ectopic lipid accumulation in the pathophysiology of the acromegalic cardiomyopathy. Journal of Clinical Endocrinology and Metabolism 2014 99 4299-4306. (doi:10.1210/jc.2014-2242)

72 Newell-Price J, Bertagna X, Grossman AB \& Nieman LK. Cushing's syndrome. Lancet 2006367 1605-1617. (doi:10.1016/S01406736(06)68699-6)

73 Chanson P \& Salenave S. Metabolic syndrome in Cushing's syndrome. Neuroendocrinology 201092 96-101. (doi:10.1159/000314272)

74 Colao A, Pivonello R, Spiezia S, Faggiano A, Ferone D, Filippella M, Marzullo P, Cerbone G, Siciliani M \& Lombardi G. Persistence of increased cardiovascular risk in patients with cushing's disease after five years of successful cure. Journal of Clinical Endocrinology \& Metabolism 199984 2664-2672. (doi:10.1210/jc.84.8.2664)

75 Faggiano A, Pivonello R, Spiezia S, De Martino MC, Filippella M, Di Somma C, Lombardi G \& Colao A. Cardiovascular risk factors and common carotid artery caliber and stiffness in patients with Cushing's disease during active disease and 1 year after disease remission. Journal of Clinical Endocrinology and Metabolism 200388 2527-2533. (doi:10.1210/jc.2002-021558)

76 Kamenicky P, Redheuil A, Roux C, Salenave S, Kachenoura N, Raissouni Z, Macron L, Guignat L, Jublanc C, Azarine A, et al. Cardiac structure and function in Cushing's syndrome: a cardiac magnetic resonance imaging study. Journal of Clinical Endocrinology and Metabolism 201499 E2144-E2153. (doi:10.1210/jc.2014-1783)

77 Toja PM, Branzi G, Ciambellotti F, Radaelli P, De Martin M, Lonati LM, Scacchi M, Parati G, Cavagnini F \& Pecori Giraldi F. Clinical relevance of cardiac structure and function abnormalities in patients with Cushing's syndrome before and after cure. Clinical Endocrinology 201276 332-338. (doi:10.1111/j.13652265.2011.04206.x)

78 Muiesan ML, Lupia M, Salvetti M, Grigoletto C, Sonino N, Boscaro M, Rosei EA, Mantero F \& Fallo F. Left ventricular structural and functional characteristics in Cushing's syndrome. Journal of the American College of Cardiology 200341 2275-2279. (doi:10.1016/ S0735-1097(03)00493-5)

79 Funder J, Duval D \& Meyer P. Cardiac glucocorticoid receptors: the binding of titriated dexamethasone in rat and dog heart. Endocrinology 197393 1300-1308. (doi:10.1210/endo-93-6-1300)

80 Sylven C, Jansson E, Sotonyi P, Waagstein F, Barkhem T \& Brönnegard $\mathrm{M}$. Cardiac nuclear hormone receptor mRNA in heart failure in man. Life Sciences 199659 1917-1922. (doi:10.1016/S0024-3205(96)00539-5)

81 Cree MG, Paddon-Jones D, Newcomer BR, Ronsen O, Aarsland A, Wolfe RR \& Ferrando A. Twenty-eight-day bed rest with hypercortisolemia induces peripheral insulin resistance and increases intramuscular triglycerides. Metabolism 201059 703-710. (doi:10.1016/j.metabol.2009.09.014)

82 Rockall A, Sohaib S, Evans DB, Kaltsas G, Isidori A, Monson JP, Besser G, Grossman AB \& Reznek R. Hepatic steatosis in Cushing's syndrome: a radiological assessment using computed tomography. European Journal of Endocrinology 2003149 543-548. (doi:10.1530/ eje.0.1490543)

83 Perseghin G, Lattuada G, De Cobelli F, Esposito A, Belloni E, Ntali G, Ragogna F, Canu T, Scifo P, Del Maschio A, et al. Increased mediastinal fat and impaired left ventricular energy metabolism in young men 
with newly found fatty liver. Hepatology $2008 \mathbf{4 7}$ 51-58. (doi:10.1002/ hep.21983)

84 Bonpace S, Perseghin G, Molon G, Canali G, Bertoli L, Zoppini G, Barbieri E \& Targher G. Nonalcoholic fatty liver disease is associated with left ventricular dysfunciton in patients with type 2 diabetes. Diabetes Care 201235 389-395. (doi:10.2337/dc11-1820)

85 Zinman B, Wanner C, Lachin JM, Fitchett D, Bluhmki E, Hantel S, Mattheus M, Devins T, Johansen OE, Woerle HJ, et al. Empagliflozin, cardiovascular outcomes, and mortality in type 2 diabetes. New England Journal of Medicine 2015373 2117-2128. (doi:10.1056/ NEJMoa1504720)

86 Marso SP, Daniels GH, Brown-Frandsen K, Kristensen P, Mann JF, Nauck MA, Nissen SE, Pocock S, Poulter NR, Ravn LS, et al. Liraglutide and cardiovascular outcomes in type 2 diabetes. New England Journal of Medicine 2016375 311-322. (doi:10.1056/ NEJMoa1603827)
Received in final form 5 April 2017

Accepted 18 April 2017

Accepted Preprint published online 18 April 2017
This work is licensed under a Creative Commons Attribution-NonCommercial 4.0 International License. 